Http://dx.doi.org/10.23925/1983-3156.2020v22i2p452-482

\title{
Desenvolvimento profissional e história da matemática: um exemplo a partir das geometrias não euclidianas
}

\section{Professional development and history of mathematics: an example based on non- Euclidean geometries}

\section{Desarrollo profesional e historia de las matemáticas: un ejemplo a partir de las geometrías no euclidianas}

\author{
Eliane Maria de Oliveira Araman ${ }^{1}$ \\ Universidade Tecnológica Federal do Paraná (UTFPR) \\ Doutorado em Ensino de Ciências e Educação Matemática - UEL \\ https://orcid.org/0000-0002-1808-2599 \\ Lucas Ferreira Gomes ${ }^{2}$ \\ Secretaria de Estado de Educação (SEDUC - MT) \\ Mestrado em Ensino de Matemática - UTFPR (Londrina/Cornélio Procópio) \\ https://orcid.org/0000-0002-4002-2218
}

\section{Resumo}

Este trabalho tem por objetivo analisar dinâmicas de aprendizagem de um curso de formação continuada ofertado a um grupo de seis professoras de Matemática que atuam na educação básica, que teve como foco algumas noções básicas das geometrias não euclidianas. Este curso teve a História da Matemática como elemento desencadeador do processo formativo. Os dados empíricos foram coletados a partir da observação participante, da gravação em áudio, de fotografias e documentos. A análise destes dados foi desenvolvida a partir do modelo interrelacional de desenvolvimento profissional. Os resultados sugerem que as docentes desenvolveram seus conhecimentos sobre os conceitos matemáticos, as potencialidades do uso da História da Matemática e refletiram sobre a prática docente.

Palavras-chave: Educação Matemática, Desenvolvimento profissional, História da matemática, Geometrias não euclidianas.

\footnotetext{
1 elianearaman@utfpr.edu.br

2 lucasgomis@hotmail.com
} 


\begin{abstract}
This work aims to analyze the learning dynamics of a continuing education course offered to a group of six Mathematics teachers who work in basic education, which focused on some basic notions of non-Euclidean geometries. This course had the History of Mathematics as a trigger for the formative process. Empirical data were collected from participant observation, audio recording, photographs, and documents. The analysis of these data was carried out based on the interrelation model of professional development. The results suggest that teachers developed their knowledge about mathematical concepts, the potential of using the History of Mathematics, and reflected on their teaching practice.
\end{abstract}

Keywords: Mathematical Education, Professional development, History of mathematics, Non-Euclidean geometries.

\title{
Resumen
}

Este trabajo tiene como objetivo analizar la dinámica de aprendizaje de un curso de educación continua ofrecido a un grupo de seis maestras de Matemáticas que trabajan en la educación básica, que se centró en algunas nociones básicas de geometrías no euclidianas. Este curso tuvo la Historia de las Matemáticas como detonante del proceso formativo. Se recopilaron datos empíricos de la observación participante, grabaciones de audio, fotografías y documentos. El análisis de estos datos se realizó con base en el modelo de interrelación de desarrollo profesional. Los resultados sugieren que los docentes desarrollaron sus conocimientos sobre conceptos matemáticos, el potencial de utilizar la Historia de las Matemáticas y reflexionaron sobre su práctica docente.

Palabras clave: Educación Matemática, Desarrollo profesional, Historia de las matemáticas, Geometrías no euclidianas. 


\section{Desenvolvimento profissional e história da matemática: um exemplo a partir das geometrias não euclidianas}

Entre as décadas de 80 e 90 ocorreram diversos debates a respeito das mudanças no ensino e na aprendizagem da Matemática, permitindo que as mais diversas pesquisas fossem desenvolvidas, em particular no campo da Educação Matemática, que entenderam tais mudanças deveria acontecer, sobretudo, a partir da ação do professor (Guskey \& Huberman, 1995). O ato de atribuir essa responsabilidade ao papel do professor fez com que as investigações posteriores passassem a dar um maior enfoque a formação docente, bem como no desenvolvimento profissional desses sujeitos. Segundo Quaresma e Ponte (2017, p. 44), o significativo "número de investigações que se sucederam sobre a mudança dos professores, a sua formação e o seu desenvolvimento profissional manifestam a preocupação da comunidade com esta temática, decorrente da alteração da atenção para ação dos professores”.

Desta forma, acontece um reconhecimento de que os processos de formação docente são extremamente complexos e que podem ser reconhecidos como processos de aprendizagem (Ponte, 1994, 1998; Strutchens et al., 2016; Ponte et al., 2017).

Considerando tais perspectivas, entende-se, neste trabalho, que a formação inicial deva ser o momento privilegiado para que o futuro professor possa desenvolver seus conhecimentos relacionados aos conteúdos que devem abordar em sala de aula e, também, os conhecimentos pedagógicos que o habilite para o exercício da docência e toda a sua complexidade. No entanto, esse espaço não é suficiente para preparar plenamente nenhum profissional e, em particular, o professor cuja ação é tão diversa e com múltiplos enfoques: científico, cognitivo, psicopedagógico, sociológico, dentre outros (Nacarato \& Paiva, 2017). Cabendo a formação continuada ser o espaço no qual o professor pode diminuir as lacunas deixadas pela sua formação inicial e, principalmente, permitir a este sujeito desenvolver-se profissionalmente por meio da reflexão apoiada na prática. 
Segundo Nacarato e Paiva (2017), o principal problema encontrado na formação continuada do professor que ensina Matemática é que, na maioria das vezes, os conhecimentos pedagógicos são explorados de forma isolada dos conteúdos a serem ensinados, ou vice-versa; fazendo com que o professor busque, sozinho, meios de articulá-los em sua prática. Assim, a formação docente deve ser repensada de tal modo que possa disseminar e construir aprendizagens, não se atendo apenas aos conteúdos a serem ensinados, mas permitir a produção de outros conhecimentos: os relacionados ao ensinar e ao aprender. "Não significa, porém, negar a importância dos conteúdos, mas partir do pressuposto de que o saber docente vai além de uma única dimensão do conhecimento" (Nacarato \& Paiva, 2017, p. 11).

Considera-se nesse trabalho que a metodologia da História da Matemática pode permitir ao professor a compreensão de conceitos matemáticos, bem como ressignificar diferentes abordagens pedagógicas para estes conceitos. Miguel (2005), Brito e Carvalho (2009), Miguel e Miorim (2019), Mendes e Chaquiam (2016), entre tantos outros pesquisadores da área apontam que esta metodologia pode contribuir substancialmente para a formação do professor que ensina Matemática, pois permite uma compreensão substantiva e epistemológica dos aspectos conceituais e das regras ligadas, intrinsicamente, aos conteúdos, além de possibilitar diferentes aprendizagens relacionadas as formas de se ensinar.

Seguindo tais entendimentos é que se propôs um curso de formação continuada para professores que atuam na Educação Básica tendo como foco explorar alguns conceitos relacionados às geometrias não euclidianas por meio da História da Matemática. Este curso, com carga horária de 12 horas, foi ofertado em meados de 2017 na cidade de Leópolis - PR, do qual participaram seis professoras que atuam na rede pública de ensino nos anos finais do Ensino Fundamental e no Ensino Médio.

O estudo desta temática se torna relevante pelo fato de que já há algum tempo que pesquisadores da Educação Matemática, como Reis (2006), Marqueze (2006) e Nascimento 
(2013), têm recomendado a abordagem de alguns conceitos relacionados a essa geometria na Educação Básica, mas em contrapartida Chavichiolo (2011) e Ribeiro (2012) apontam que a formação docente não tem permitido aos professores desenvolverem seus conhecimentos sobre as geometrias não euclidianas.

Desta forma, a presente pesquisa tem como objetivo analisar dinâmicas de aprendizagem do curso de formação continuada ofertado, buscando identificar os contributos deste para a formação das docentes participantes.

\section{O desenvolvimento profissional do professor}

A ação docente é um campo de estudo emergente. Cercada por diversas complexidades, o professor desenvolve inúmeras atividades que são inerentes do seu fazer pedagógico, como planejar uma aula, organizar o ambiente da aula, gerenciar os conteúdos a ser trabalhado, avaliar, buscar diferentes abordagens para explorar os conceitos a serem ministrados, entre outros. Todavia, no momento em que o professor adquire sua habilitação profissional ele está longe de ser um profissional acabado e amadurecido, na medida em que os conhecimentos que ele adquiriu ao longo dessa formação são insuficientes para o exercício das suas funções ao longo de sua carreira, reconhecendo, desta forma, a necessidade de crescimento e de aquisições diversas, assumindo ele próprio o comando de seu desenvolvimento (Ponte, 1994).

Neste viés, é possível entender que a qualificação profissional deva ser o meio pelo qual o professor possa ampliar e/ou aprimorar a sua prática. Além de ser indispensável para que ele possa acompanhar mudanças no currículo, nas abordagens de ensino e nas condições de trabalho que são constantes (Day, 2001). Porém, o professor não deve ser entendido como um receptor de formações, mas deve ser considerado com um ser repleto de potencialidades e necessidades diversas, por isso precisa ser influenciado a se desenvolver (Ponte, 1994; Ponte et al., 2017). Na década de 90, muitos pesquisadores da Educação Matemática voltaram seus 
estudos para o desenvolvimento profissional do professor de Matemática; entendida naquele contexto como sendo:

[...] para além de uma etapa meramente informativa; implica adaptação à mudança com o fim de modificar as atividades de ensino-aprendizagem, alterar as atitudes dos professores e melhorar os resultados escolares dos alunos. O desenvolvimento profissional de professores preocupa-se com as necessidades individuais, profissionais e organizativas. (Heideman, 1990, p. 4)

Evidenciando que esse processo é aquele pelo qual o professor pode ampliar seus conhecimentos, melhorar a sua prática e aprimorar suas atitudes (Ponte et al., 2017). Contudo, os vários anos de estudos e investigações sobre esta temática possibilitaram que fossem elaborados diversos modelos procuram descrever o processo de desenvolvimento profissional do professor. Fazendo com que a concepção de formação docente fosse se modificando ao longo desse período, sendo entendida na atualidade como a passagem de "um processo induzido externamente (formação), processo em que estes são relativamente passivos, para a concepção de desenvolvimento profissional como um processo participado e complexo que envolve a aprendizagem" (Quaresma \& Ponte, 2017, p. 48).

Nesta perspectiva, Ponte (1998), Day (2001) e Ponte et al. (2017) destacam que o desenvolvimento profissional refere-se aos processos de aprendizagem relacionados com o exercício da docência, decorre ao longo da vida profissional do professor e pressupõe o seu investimento em questões diversas, incluindo as que se relacionam diretamente com o ensino das disciplinas a qual ele ministra. Clarke e Hollingsworth (2002, p. 948) contribuem ao afirmar que a concepção mudou de programas 'que 'mudam' o conhecimento dos professores para professores como aprendizes ativos que moldam o seu próprio crescimento/desenvolvimento profissional através da participação reflexiva em programas de desenvolvimento profissional e na sua própria prática". Assim, o desenvolvimento profissional dos professores diz respeito às diversas experiências de aprendizagem (naturais, planejadas e conscientes) realizadas pelo 
benefício direto ou indireto, contribuindo para melhorar o desempenho do professor dentro da sala de aula (Day, 2001), apropriando-se particularmente de uma atitude profissional que remete para uma prática de questionamento. É, também, o processo através do qual os docentes, sozinhos e em conjunto com os outros, reveem e valorizam o seu papel como agentes de mudança e como construtores críticos do conhecimento e das competências ao longo da sua vida como professores (Day, 2001). Em si, é um movimento de longo prazo, que integra diferentes tipos de oportunidades e de experiências, planejadas sistematicamente, de forma a promover o crescimento dos professores. Para Day (2001):

Todas as experiências espontâneas de aprendizagem e as atividades conscientemente planificadas, realizadas para benefício, direto ou indireto, do indivíduo, do grupo ou da escola e que contribuem, através destes, para a qualidade da educação na sala de aula. É o processo através do qual os professores, enquanto agentes de mudança, reveem, renovam e ampliam, individual ou coletivamente, o seu compromisso com os propósitos morais do ensino, adquirem e desenvolvem, de forma crítica, juntamente com as crianças, jovens e colegas, o conhecimento, as destrezas e a inteligência emocional, essenciais para uma reflexão, planificação e prática profissionais eficazes, em cada uma das fases das suas vidas profissionais. (Day, 2001, p. 20)

Este processo de desenvolvimento pode ser baseado em diversas estratégias, que segundo Ponte (1994) a via dos projetos profissionais, ao lado de outras atividades que visam a prática do autoquestionamento e da reflexão da própria prática; reconhecendo e experimentando materiais e recursos, estudando e investigando saberes constituídos, relativo aos conteúdos e a questões de ordem pedagógicas.

Baseando-se nestas reflexões, emerge o modelo de desenvolvimento profissional do professor considerado neste trabalho: o proposto por Clarke e Hollingsworth (2002) referido como modelo inter-relacional de desenvolvimento profissional (Figura 1). 
Figura 1.

Modelo inter-relacional de desenvolvimento profissional

(Clarke \& Hollingsworth, 2002, p. 951)

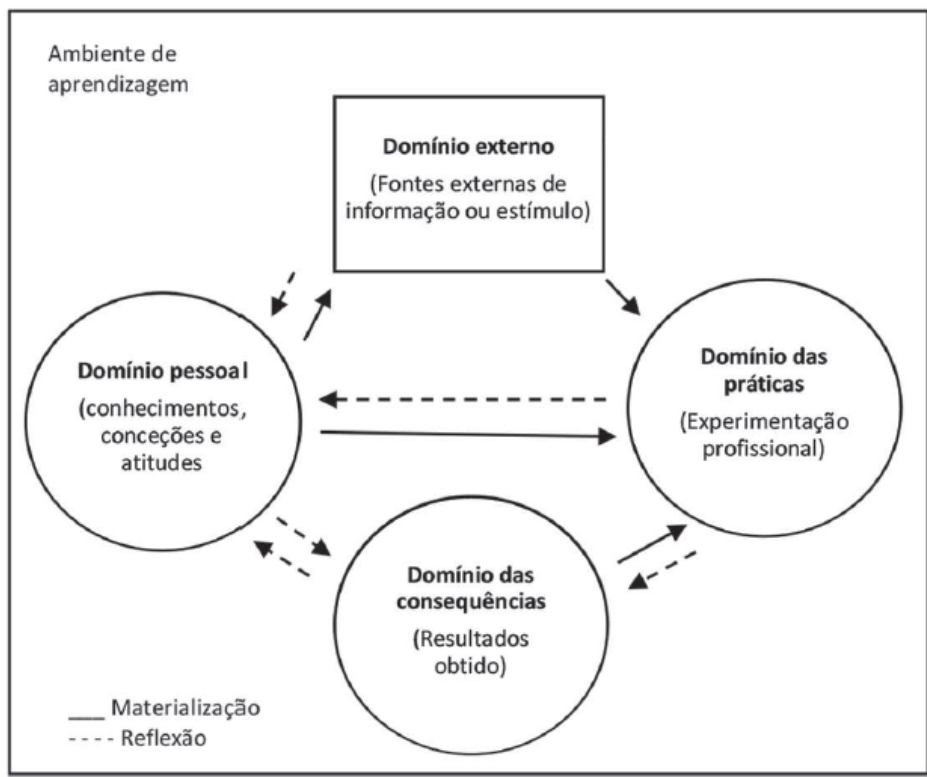

Este modelo surgiu em oposição a outros que foram propostos e, que segundo Clarke e

Hollingsworth (2002), têm estruturas estritamente lineares e, por isso, não reconhecem a complexidade dos processos de aprendizagem dos professores. No entendimento de Quaresma e Ponte (2017),

Neste modelo destaca-se a estrutura inter-relacional, sugerindo que a aprendizagem acontece através dos processos de materialização e reflexão, em quatro domínios: (i) o pessoal, que inclui os conhecimentos, as crenças e as atitudes do professor; (ii) o das práticas de ensino, que é onde ocorre a experimentação profissional e que para os autores corresponde à sala de aula; (iii) o das consequências na aprendizagem dos alunos, onde os professores reconhecem os resultados das alterações realizadas na prática; e (iv) o externo que apresenta uma forma diferente dos restantes domínios, porque representa a fonte de informação ou estímulo para a aprendizagem que é externa e independente do professor. Assim, o desenvolvimento profissional resulta da reflexão que os professores realizam nos vários domínios, mas também da experimentação de novas formas de atuação. (Quaresma \& Ponte, 2017, p. 49)

No que concerne ao conhecimento do professor que ensina Matemática, Ponte (2012) destaca o conhecimento didático que diz respeito à prática letiva e tem sua base mais aprofundada na especificidade da disciplina. Tal conhecimento é dividido por este pesquisador 
em quatro vertentes. A primeira delas diz respeito ao conhecimento da Matemática enquanto disciplina escolar, a forma de representação desses conceitos, a percepção que o professor tem a respeito da Matemática escolar e, por consequência, aquilo que mais valoriza, especificamente os aspectos processuais e conceituais. A segunda vertente é o conhecimento do aluno e dos seus processos de aprendizagem, isto é, relaciona-se com a forma como os alunos aprendem, se relacionam, constroem seu conhecimento, entre outros aspectos. Já a terceira vertente refere-se ao currículo, isto é, ao "conhecimento das grandes finalidades e objetivos do ensino da Matemática, bem como a organização dos conteúdos, o conhecimento dos materiais e das formas de avaliação a utilizar" (Ponte, 2012, p. 87). E, por fim, a última vertente é conhecimento da prática letiva, que, para o respectivo pesquisador, é cerne fundamental do conhecimento didático e inclui a prática do ensino nas aulas de Matemática, relacionada "as formas de organização do trabalho dos alunos, a criação de uma cultura de aprendizagem na sala de aula, o desenvolvimento e a regulação da comunicação e a avaliação das aprendizagens dos alunos e do ensino do próprio professor" (Ponte, 2012, p. 88).

Segundo Quaresma e Ponte (2017), por assumir tais dimensões o conhecimento didático está incluído no domínio pessoal apresentado no modelo interrelacional de desenvolvimento profissional de Clarke e Hollingsworth (2002). Neste viés, o presente trabalho busca identificar, a partir deste modelo, as aprendizagens possibilitadas pela História da Matemática em relação às geometrias não euclidianas.

\section{A História da Matemática e a formação do professor que ensina matemática}

Nos últimos anos, tanto no Brasil quanto em outros países, muito se tem discutido acerca das potencialidades crítica e formativa da participação orgânica da História da Matemática na Educação Matemática escolar e, como decorrência, também na formação de professores de Matemática (Miguel, 2005). Tais discussões têm motivado diversas pesquisas, 
contribuindo com diversos argumentos favoráveis a abordagens históricas no ensino da Matemática e na formação de professores.

Sob tal óptica, Araman e Batista (2013) defendem que a História da Matemática, em seu enfoque epistemológico e metodológico, pode ser um fator contributivo para a formação do professor que ensina Matemática, principalmente no que diz respeito à estruturação de seus conhecimentos. Desta forma, esta metodologia apresenta-se como um caminho pelo qual os professores podem construir aprendizagens. Aprendizagens estas influenciadas pela compreensão da natureza da Matemática, de conceitos e métodos que podem possibilitar uma compreensão de como se dá o desenvolvimento do conhecimento matemático (Araman, 2011).

Assim, entende-se que o nível de competência Matemática do professor na sua formação deve permitir a compreensão dos conteúdos matemáticos que pode ser alcançada por meio dos elementos históricos. Contudo, somente o conhecimento histórico não é suficiente; os professores devem desenvolver tal perspectiva de conhecimento no sentido da sua correta utilização educacional (Mendes \& Chaquiam, 2016).

Para tanto, a formação do professor, baseada na História da Matemática, deve ser pensada de tal modo a permitir a compreensão de como os conceitos matemáticos se desenvolveram, mas levando em consideração diferentes abordagens. Dentre as quais é possível citar as narrativas, os problemas, a resolução de problemas históricos, as investigações, os vídeos, reflexões sobre os contextos históricos, entre tantas outras abordagens que podem permitir a construção de conhecimentos que visam o desenvolvimento profissional do professor.

De acordo com Miguel (2005) a História da Matemática tem uma influência decisiva no espírito do professor e na sua atitude em relação à própria Matemática, por isso que ela deve permear a formação docente. Além disso, ele afirma que esses sujeitos teriam motivações para 
ensiná-la e, claro, esse modo de ensinar pode ser influenciado positivamente por essa nova atitude possibilitada pelo conhecimento advindo da História da Matemática.

Corroborando com essas propostas, Batista e Luccas (2004) defendem que o uso pedagógico da História se constitui como instrumento fortalecedor da prática docente, a favorecendo de diversas formas, dentre elas na promoção de debates acerca dos valores cognitivos da ciência. Indo ao encontro de tal perspectiva, Mendes e Chaquiam (2016) afirmam que a:

[...] história pode ser tomada como um aporte para esclarecimentos de cunho epistemológico e didático que poderão contribuir para o professor explicar e orientar a organização das matemáticas escolares. Nesse sentido as informações históricas poderão ser utilizadas para auxiliar o professor de matemática a melhorar o planejamento e a execução de suas explanações durante as aulas de matemática, bem como para justificar os modos de produção matemática no tempo e no espaço. (Mendes \& Chaquiam, 2016, p. 17)

Araman e Batista (2013) apontam alguns contributos possibilitados pela História da Matemática para o desenvolvimento profissional professor: compreensão da natureza do conhecimento matemático, compreensão dos conteúdos matemáticos, formação metodológica e a visão interdisciplinar do professor.

Além disso, os estudos históricos proporcionam uma visão mais ampla do conhecimento matemático, em contraste com a visão especializada - e, por vezes, compartimentada - da formação inicial. Essa visão permite que o professor, por meio dos estudos históricos, observe as relações existentes entre as várias áreas do conhecimento científico e como os conhecimentos de uma área podem contribuir para o desenvolvimento de outras (...). Salientamos, ainda, a interface com os conhecimentos pedagógicos do professor. Ao estudar e desenvolver uma abordagem histórica para o ensino, o professor aprende a necessidade da aproximação de todas essas áreas. (Araman \& Batista, 2013, p. 5)

Mediante tantas recomendações favoráveis a inserção desta metodologia na formação do professor que ensina Matemática é possível dizer que - ao permitir que o professor amplie seus conhecimentos sobre como os conceitos se desenvolveram, sobre os conteúdos, sobre estratégias de como se abordar esses tópicos, sobre como a Matemática tem se estruturado ao 
longo do tempo, sobre como essa ciência tem se evoluído e ganhado forma, entre tantos outros saberes - as abordagens advindas da História da Matemática podem favorecer diversas mudanças nas crenças dos professores, nas formas como ele concebe o ensinar e o aprender Matemática, na maneira como ele estrutura seus conhecimentos matemáticos, entre tantos outros contributos que permitem ao professor desenvolver-se profissionalmente.

\section{Percursos metodológicos}

Esta investigação, de natureza qualitativa e interpretativa (Bogdan \& Bliken, 1994), realizada no campo da Educação Matemática resulta das reflexões de um estudo desenvolvido sobre um curso de formação continuada ${ }^{3}$ ofertado em meados de 2017.

O curso foi ministrado em uma escola pública do município de Leópolis-PR, sob a concessão do Núcleo Regional de Educação e da autorização da equipe diretiva do colégio. Dividido em três encontros aos sábados, ele teve uma duração doze horas. Após a divulgação em todas escolas do município, um grupo de seis professoras que atuavam nos anos finais do Ensino Fundamental e no Ensino Médio da rede pública de ensino se dispuseram a realizar tal formação. Sobre elas é possível destacar que todas possuíam a mesma formação: licenciatura em ciências, que concedia a habilitação para o ensino da Matemática e Ciências nos anos finais do Ensino Fundamental (licenciatura curta), e que permitia ao professor cursar uma complementação (licenciatura plena) em Matemática (4 professoras), Física (1 professora), Química (1 professora) ou Biologia (1 professora - a mesma da Química), além de todas possuírem cursos de especialização latu sensu na área da educação; cabe salientar que todas são efetivas e já possuem, em média, mais de quinze anos de atuação.

\footnotetext{
${ }^{3}$ Este curso é parte integrante da pesquisa de mestrado de um dos autores deste trabalho, Programa de Pósgraduação em Ensino de Matemática (PPGMAT) da Universidade Tecnológica Federal do Paraná - Campus Londrina e Campus Cornélio Procópio.
} 
Todos os encontros da formação foram registrados em gravação de áudio, de fotografias e na recolha documental ${ }^{4}$, não deixando de lado algo fundamental: a observação participante. Destaca-se que para as docentes ficou de comum acordo que os dados coletados seriam fontes de reflexão, mas assumindo o compromisso de manter o anonimato a fim de que elas pudessem se expressar com mais naturalidade. Isso, por entendermos que o mais relevante são as ideais expressas pelos participantes, isto é, mais relevante do que quem disse ou fez é o que disse e o que fez.

Este curso de formação continuada para professores de Matemática teve como base algumas noções elementares das geometrias não euclidianas, especificamente a respeito das geometrias hiperbólica e elíptica. Além de possibilitar uma reflexão sobre tais conceitos, o foco também era permitir aos professores participarem de uma formação que os levassem a vivenciar o uso pedagógico da História da Matemática por meio de tarefas investigativas e de vídeos didáticos. As temáticas abordadas ao longo do curso foram exploradas da seguinte forma: $1^{\circ}$ encontro - o conceito e a origem das geometrias não euclidianas; $2^{\circ}$ encontro: a ideia de retas paralelas e de triângulos nas geometrias não euclidianas; $3^{\circ}$ encontro: os quadriláteros nas geometrias não euclidianas e avaliação do curso.

Cada tema era composto por uma sequência semelhante: um conjunto de tarefas e um vídeo didático que formaliza as ideias exploradas nas atividades a partir do contexto histórico de criação dos mesmos, além de abordar outros conceitos que não foram abordados na tarefa, possibilitando, assim, novas reflexões. As tarefas propostas têm como princípio a abordagem histórico-investigativa. Segundo Nascimento (2013, p. 55) esta abordagem incita ao desenvolvimento da "capacidade de indagar questões dadas para averiguação e que tenha

\footnotetext{
${ }^{4}$ Os dados foram coletados a partir da autorização de todas as professoras participantes por meio da assinatura do Termo de Consentimento Livre e Esclarecido.
} 
possibilidade de progredir com seu raciocínio lógico-matemático ampliando, mediante confrontos, as definições dos elementos geométricos e suas propriedades".

As tarefas foram pensadas a partir de um mesmo princípio: refletir sobre algumas propriedades e características que são válidas na geometria euclidiana plana e que se modificam nas geometrias hiperbólica e elíptica; sendo cada uma estruturada da seguinte forma: $1^{\text {o }}$ Conhecimentos prévios: retomada dos conceitos da geometria euclidiana plana que são prérequisitos para realização das tarefas; $2^{\circ}$ - Recorte histórico: apresentação dos elementos históricos que exploram o desenvolvimento dos conceitos matemáticos abordados nas tarefas; $3^{\text {o }}$ - Objetivo: delimitação do objetivo a ser alcançado com a realização da tarefa; $4^{\circ}$ Procedimentos: formalização da tarefa, isto é, delimita o que deve ser executado.

Completando tais sequências têm-se os vídeos didáticos. Estes foram produzidos em forma de animação, trazendo um avatar chamado Eugênio que, com o auxílio imagens, textos, mudança de cenários, entre outros elementos, exploram a criação das geometrias não euclidianas, apresenta algumas definições, explora propriedades, faz alguns questionamentos e reflexões entre outros elementos relacionados à geometria euclidiana plana e às geometrias não euclidianas (hiperbólica e elíptica). Como mostra a Figura 2:

Figura 2.

Vídeo sobre os triângulos nas geometrias não euclidianas

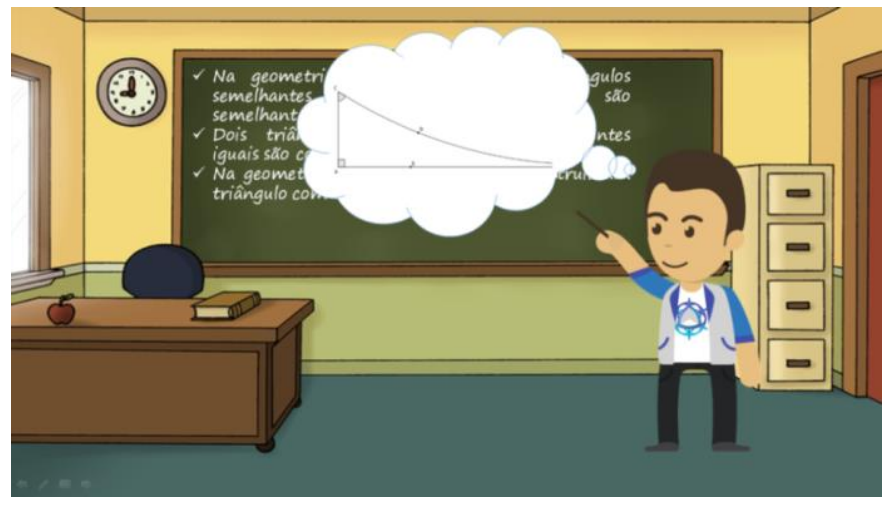

No que diz respeito à análise das dinâmicas de aprendizagem das docentes, esta foi iniciada a partir da indução analítica, tendo em vista os agrupamentos dos dados de modo a 
sistematizá-los (Goetz \& Lecompte, 1984). Feito isso, foi possível empregar o do modelo de desenvolvimento profissional apresentado por Clarke e Hollingsworth (2002), buscando identificar, de modo sistemático e aprofundado, nas tarefas realizadas as aprendizagens desenvolvidas pelas professoras considerando duas das quatro vertentes do conhecimento didático indicadas por Ponte (2012): o conhecimento dos conceitos matemáticos e seus fundamentos (primeira vertente) e o conhecimento sobre a prática letiva, relacionado as formas de se ensinar do professor (quarta vertente). Esta escolha consiste na intencionalidade da formação que se propunha e na forma como as atividades foram pensadas, estruturadas e propostas.

Todavia, deve-se ponderar que o modelo de Clarke e Hollingsworth (2002) considera o domínio das práticas as atividades que perpassam a sala de aula, porém assim como Quaresma e Ponte (2017) consideramos que outros espaços de formação que permitem o contato com experiências profissionais que se relacionam ao conhecimento da prática pedagógica, devam ser considerados ambientes de desenvolvimento profissional do professor, uma vez que eles podem influenciar o conhecimento desses sujeitos. Assim, entendemos que as formas de experimentação profissional vivenciadas ao longo do curso possibilitaram a construção de aprendizagens que se enquadram, essencialmente, no domínio pessoal que é parte integrante do domínio das práticas.

\section{O percurso formativo: resultados e discussão}

No início do primeiro encontro, a fim de inserir as professoras na temática do curso e permitir que elas pudessem apresentar suas percepções, seus pensamentos, seus conhecimentos, entre outros aspectos inerentes dos conhecimentos a serem abordados ao longo do curso, propôs-se o seguinte questionamento: o que você entende por geometrias não euclidianas? Neste momento do trabalho há de destacar as estranhezas manifestadas pelas professoras ao receberem tal questionamento: 
P35: Olha, me lembro de ter visto algo num curso ministrado lá no núcleo em Cornélio, mas agora me fugiu da memória. Mas... Mas, por se tratar de geometria acredito que ela diz respeito às formas, retas, ângulos, quadrados, círculos. Todos os elementos da geometria.

P5: Eu também acho, porque na geometria a gente vê isso, a gente estuda isso teorema de Pitágoras, Teorema de Thales, triângulo retângulo, então se é geometria a gente irá ver isso.

P2: Gente! Mas esse nome é diferente, é não euclidiana. Nos livros didáticos não me recordo de ter visto, na graduação vi apenas área, volume... Ah! Essas coisas.

P1: Verdade esse nome é algo. Mas não sei, se é não euclidiana quer dizer que é diferente da euclidiana. Não é?

De modo que elas compreendessem a ideia de geometria não euclidiana e que pudessem visualizar a proposta do curso de formação continuada ali proposto, entregamos a cada uma delas um balão vazio, assim solicitamos a elas que desenhassem uma forma geométrica nele e em seguida o enchesse (Figura 3). Segue um dos resultados:

Figura 3.

Forma geométrica feita no balão

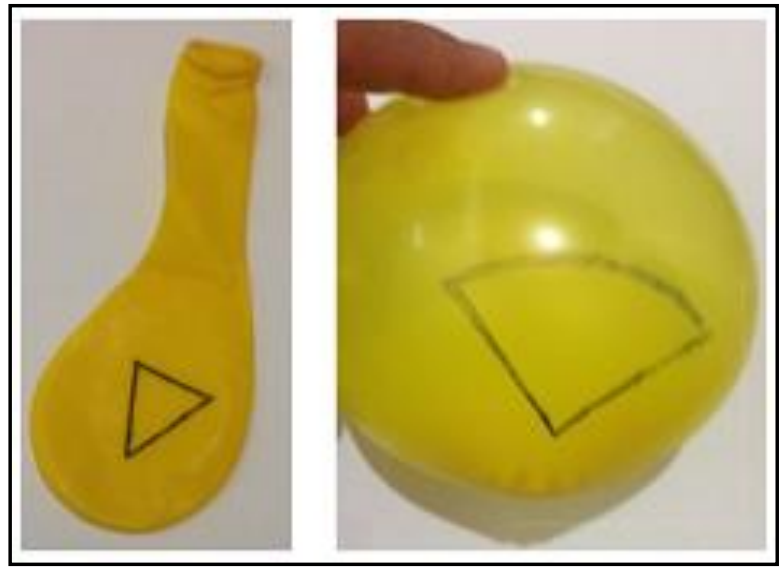

A partir desta atividade, indagamos as professoras sobre as modificações que sofreram as figuras construídas por elas após inflarem o balão. Na percepção delas:

P3: A figura manteve suas linhas, seus pontos, mas mudou a sua curvatura.

P5: De repente as linhas ficaram tortas, porém manteve a característica inicial.

P6: As retas não ficaram tão perfeitas, mas manteve o padrão.

\footnotetext{
${ }^{5}$ Como destacado, para preservar a imagem das professoras usaremos os códigos P1 para indicar a primeira professora, P2 para segunda e assim sucessivamente.
} 
Após, discutirmos as ideias foi apresentado o primeiro vídeo “A origem das geometrias não euclidianas" ${ }^{\prime 6}$ que aborda como surgiram estas geometrias, bem com algumas características que são próprias destas geometrias e que as diferencia da geometria euclidiana plana, o que poderia contribuir para a compreensão das modificações sofridas pelas figuras nos balões. Nele é explorado os cinco postulados de Euclides, as tentativas falhas de prova do quinto postulado (postulados das paralelas), as criações de Lobachevsky, Bolyai e Gauss ao negarem o quinto postulado até chegar ao surgimento das geometrias não euclidianas. Ao perceber que estas geometrias consideram outros espaços para o seu desenvolvimento, como no caso a geometria esférica que é desenvolvida sob a superfície de uma esfera, uma das professoras chegou a seguinte conclusão:

P2: Nossa! É por isso que a figura fica curva! Era a superfície, uma geometria esférica!

Partindo de um estímulo exterior (domínio externo), embasado no questionamento inicial, na tarefa do balão e no vídeo didático explorado, as professoras foram conduzidas a refletir sobre o que são as geometrias não euclidianas e como elas surgiram (seta tracejada 1 na Figura 4). Esta reflexão levou a alterações no conhecimento das professoras de que a geometria não se limita a geometria plana ou geometria espacial, mas que existem outras geometrias dentre elas as geometrias não euclidianas; além disso, elas puderam compreender o que são estas geometrias e como elas surgiram (aprendizagem na vertente do conhecimento da Matemática). Estes novos conhecimentos possibilitaram às docentes refletirem sobre o ensino da geometria em sala de aula, tanto nas formas de se ensinar quanto nos conteúdos ministrados (seta tracejada 2), mobilizando conhecimentos que dizem respeito a vertente do conhecimento da prática letiva.

P4: Quantas vezes ensinamos partes da geometria sem considerar esses pequenos elementos que fazem toda a diferença. Eu mesmo... É... Quantas vezes ensinamos a

\footnotetext{
${ }^{6}$ Disponível em: https://www.youtube.com/watch?v=eqjKgzx7fLk\&t=4s. Acesso em: 01/04/2020.
} 
formas e deixamos de chamar a atenção que elas estão no plano. Que o que estamos falando é sempre de uma superfície plana, ela é o nosso ponto de referência.

P3: Verdade! A gente ensina um monte de conceito solto e, muitas vezes, esquecemos de amarrá-los e por conta de nem sempre dar sequência em pegar a turma no outro ano os alunos ficam com muitas lacunas na cabeça.

P1: Isso mesmo.

P4: Eu mesma tenho vários assuntos que acabo deixando de lado porque eu não domino. Muitos mesmo. Nessa geometria tenho muita dificuldade, porque é muita propriedade, muitas fórmulas e a gente não lembra. E até para os alunos, a gente sente neles essa dificuldade.

P5: Eu também. Mas sempre procuro pegar os livros e ver vídeos na internet. Quando vou preparar as minhas aulas, mas a geometria confunde muito a gente e os alunos também.

Figura 4.

Dinâmicas de aprendizagem das professoras na primeira parte do curso

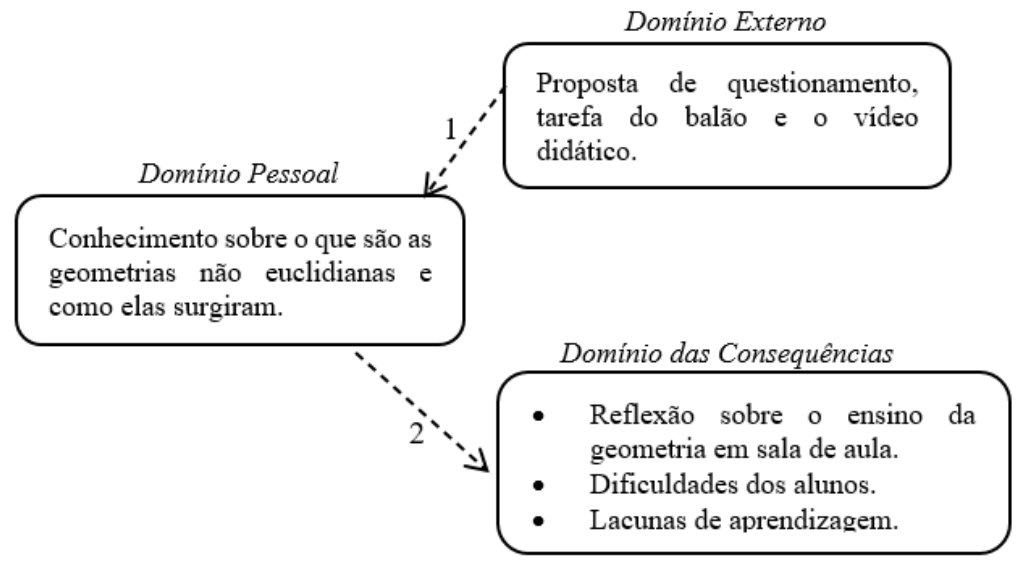

Outro tópico explorado no curso foi a ideia de retas paralelas, esta abordagem aconteceu no segundo encontro. As tarefas propostas sobre tal temática foram as seguintes: 


\section{Quadro 1. \\ Atividades sobre as retas paralelas nas geometrias não euclidianas}

Na geometria euclidiana plana, duas retas distintas de um plano são paralelas, quando não têm um ponto comum. Essa ideia foi definida em Os Elementos, escrito Euclides por volta de 300 a.C., nesta obra estão os famosos cinco postulados de Euclides e o último deles remetem a ideia de paralelismo:

"E, no caso de uma reta, caindo sobre duas retas, faça os ângulos interiores e do mesmo lado menores do que dois retos, sendo prolongadas as duas retas, ilimitadamente, encontraram-se no lado no qual estão os menores do que dois retos" (Bicudo, 2009, p. 98).

Este foi reescrito de diversas maneiras, sendo a mais conhecida a proposta por John Playfair em meados de 1795: "para toda reta $l$ e todo ponto $P$ fora de $l$, pode-se traçar uma única reta paralela a $l$, que passe por $P$ ".

1) Vamos construir tais retas paralelas e verificar a veracidade deste postulado para a geometria euclidiana plana, considerando como o plano a folha de sulfite, proceda da seguinte forma:

a) Trace uma reta e a denomine de $r$;

b) Marque um ponto $P$ fora da reta $r$;

c) Construa um arco de centro $P$ de modo que este intersecte a reta $r$;

d) Marque o ponto $A$ dessa interseção;

e) Construa outro arco de mesmo raio, com centro em $A$, que intercepte a reta $r$;

f) Marque o ponto $B$ dessa intersecção;

g) Após isto, construa um arco de centro em $B$, de mesmo raio, e que intersecte em algum ponto do arco de centro $P$.

h) Chame o ponto da interseção de $Q$.

i) Trace uma reta que passe pelos pontos $P$ e $Q$ e chame-a de reta $s$.

A partir dessa construção, responda a reta $s$ construída é paralela a $r$, tomando como referência a geometria euclidiana plana?

2) Como vimos no primeiro vídeo Lobachevsky propôs uma ideia de retas paralelas diferente da proposta por Euclides em sua obra $O s$ Elementos, pois "chegou à conclusão de que, se o espaço muda a imagem e a definição também mudará" (Nascimento, 2013). Assim, ele propôs que o quinto postulado de Euclides fosse substituído pelo seguinte: "existe uma reta $\mathrm{r}$ e um ponto $P$ que não pertence a $r$ tal que por $P$ passa ao menos duas retas paralelas à reta $r$ " (Camargo, 2012, p.49), entendendo reta como geodésica do espaço hiperbólico. A partir dessa substituição ele deu forma a uma nova geometria, a chamada geometria hiperbólica.

Vamos verificar essa afirmação. Sobre uma superfície hiperbólica, representado pela superfície de biscuit, execute os mesmos passos realizados no item anterior.

A partir dessa construção, é possível dizer que a reta que passa por $s$ é paralela a $r$, tomando como referência a definição de reta paralela na geometria euclidiana plana? Por quê?

3) Quaisquer duas retas em um plano, desde que não sejam paralelas, têm um ponto de encontro. Contudo:

"Nesta Geometria, as retas são consideradas como os círculos máximos, chamados de geodésicas, que dividem a esfera em duas partes iguais, assim como a linha do equador ou as linhas de longitude da Terra. Esses círculos são chamados de máximos, pois são os maiores círculos que podem ser traçados na esfera e desta forma são os caminhos com menor curvatura. Sendo assim, tem-se uma analogia com as retas no plano euclidiano, pois o caminho mais curto formado por dois pontos da esfera é um arco do círculo máximo que passa por estes pontos. Dois grandes círculos se cruzam, de modo que não existem retas paralelas nesta geometria”. (CAMARGO, 2012, pp.57)

Desta forma, Riemann propôs que o quinto postulado de Euclides fosse substituído por "Dada uma reta $L$ e um ponto $P$ não pertencente a $L$, não existe reta paralela a $L$ passando por $P$ ” (Camargo, 2012, p. 72).

Verifique essa afirmação. Para isso sobre uma superfície esférica, representada pela bola de isopor, tente realizar os mesmos passos da construção anterior.

A partir dessa construção, é possível dizer que a reta que passa por $s$ é paralela a $r$, tomando como referência a definição de reta paralela na geometria euclidiana plana? Por quê?

4) A partir das atividades e construções realizadas nos três itens anteriores, responda:

a) Descreva como as retas ficaram nessas superfícies.

b) As retas foram construídas em três superfícies distintas, mesmo assim elas perderam suas caraterísticas principais?

c) Em que divergem as características das retas paralelas construídas?

d) A partir das construções a que conclusões você chegou? São as mesmas apresentadas no vídeo?

e) Para você, qual a relevância dessas propriedades para Matemática e para o seu contexto histórico? 
Como pode-se observar, as tarefas propõem a mesma construção de retas paralelas em três superfícies diferentes: sulfite (representando o plano - geometria euclidiana), sela de biscuit (representando a pseudoesfera - geometria hiperbólica) e a bola de isopor (geometria esférica). Após cada construção são indicados alguns questionamentos que tinham como objetivo conduzir as professoras a visualizarem as modificações da ideia de retas paralelas do referencial euclidiano (geometria plana) para o não euclidiano (geometrias hiperbólica e elíptica), conforme a Figura 5:

Figura 5.

Construção das retas paralelas

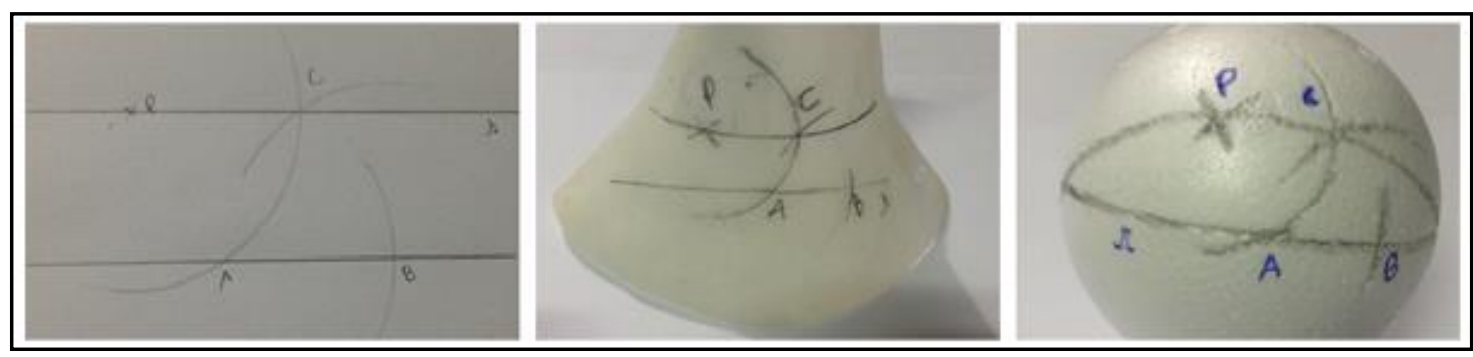

$\mathrm{Na}$ segunda tarefa tivemos que interromper para formalizar a ideia de pseudoesfera (superfície hiperbólica), já que, segundo elas, nunca tinham visto aquela forma geométrica. Mas fomos as auxiliando de modo que todas finalizassem as construções e pudessem refletir sobre elas. Segue parte do diálogo realizado no fim das construções:

P5: Quando fala em paralelismo a gente já tem em mente aquelas retas retinhas... É... uma do lado da outra. Como que a gente não para pra pensar fora disso, como que a gente fica preso nisso.

P2: Bem isso! Eu nunca pensei nisso. Nunca vi. Como é interessante né. A gente vive em uma esfera. Quando a gente anda em linha reta é uma curva, não é reta.

P3: Então... no cotidiano é muito mais comum você vê uma reta curva, do que uma reta reta.

P6: Sim, agora acho que vamos olhar essas coisas de outra forma.

P2: É engraçado como que não paramos pra pensar nisso, para mim paralela é paralela, não muda. Para mim sempre ia existir. 
Para complementar as ideias das tarefas, foi apresentado outro vídeo didático "Retas paralelas nas geometrias não euclidianas"7 . Este vídeo aborda a ideia de retas paralelas com base nas criações Lobachevsky em relação na geometria hiperbólica e as criações de Bolyai em relação a geometria esférica, trazendo as principais características, propriedades e exemplos deste conceito que não foram comtempladas nas tarefas. Finalizando esta sequência, foi possível identificar que, de início, as docentes acreditavam que independentemente da geometria considerada o paralelismo acontecia, o que já era internalizado a partir do que haviam aprendido ao longo de suas vidas acadêmicas e do que ensinavam em suas aulas, fortemente apoiadas nas ideias da geometria euclidiana plana. Por meio da experimentação e visualização proposta foi possível provocar mudanças em suas perspectivas.

Esta etapa do curso tem por base processos de reflexões possibilitadas pelo domínio externo (tarefas histórico-investigativas e o vídeo didático), como mostra a Figura 6. Tais tarefas contribuíram para discussões e reflexões que vão além dos conceitos matemáticos abordados, trazendo á tona elementos que se relacionam ao fazer pedagógico, isto é, além de explorar conceitos que, para muitas delas, ainda eram desconhecidos (desenvolvimento de conhecimentos na vertente da Matemática), permitimos que elas vivenciassem uma abordagem pedagógica com recursos fundamentados na História da Matemática (conhecimento na vertente prática letiva). Assim, a realização das tarefas propostas, os questionamentos e os vídeos agiram como elemento condutor de reflexão o que influenciou (seta tracejada 1 - Figura 6) nos conhecimentos das professoras (domínio pessoal) que as estimularam (seta tracejada 2 - Figura 6) a refletir sobre a própria prática, ou seja, na prática do ensino da Matemática.

P4: Hoje pude perceber como faz a diferença o conceito e saber o conceito e como ele surgiu. Quantas vezes ficamos presos no conceito... é... por ele... só por ele... não buscamos mostrar o porquê aquele conceito foi criado... quem criou... como criou... P3: É verdade... hum... é como se pularmos uma etapa. A gente ensina o conceito pelo conceito.

\footnotetext{
${ }^{7}$ Disponível em: https://www.youtube.com/watch?v=ZvuzbE0FP3E. Acesso em: 01/04/2020.
} 
P4: É muito mais fácil saber o porquê primeiro e depois saber o que.

P3: É exatamente isso.

P2: Lembro na faculdade o pouquinho que vimos! Como era chato (Risos). Mas você vê na prática como vimos agora é muito mais interessante... o traçado na bolinha... você vê aqueles conceitos criando forma... é bem mais prático... é diferente e é legal. P4: Acredito que não é só eu, mas... mas minhas amigas aqui tivemos muitas ideias para sala, esse trabalho tem sido muito rico pra nós.

P5: Isso é verdade. Poderia ter mais deste. Quantas vezes queremos coisas diferentes pra trabalhar, mas nada chega até nós ai... as vezes... as vezes tentamos. Teoria. Só teoria. Nada do que estamos vendo.

Figura 6.

Dinâmicas de aprendizagem das professoras sobre a ideia de retas paralelas

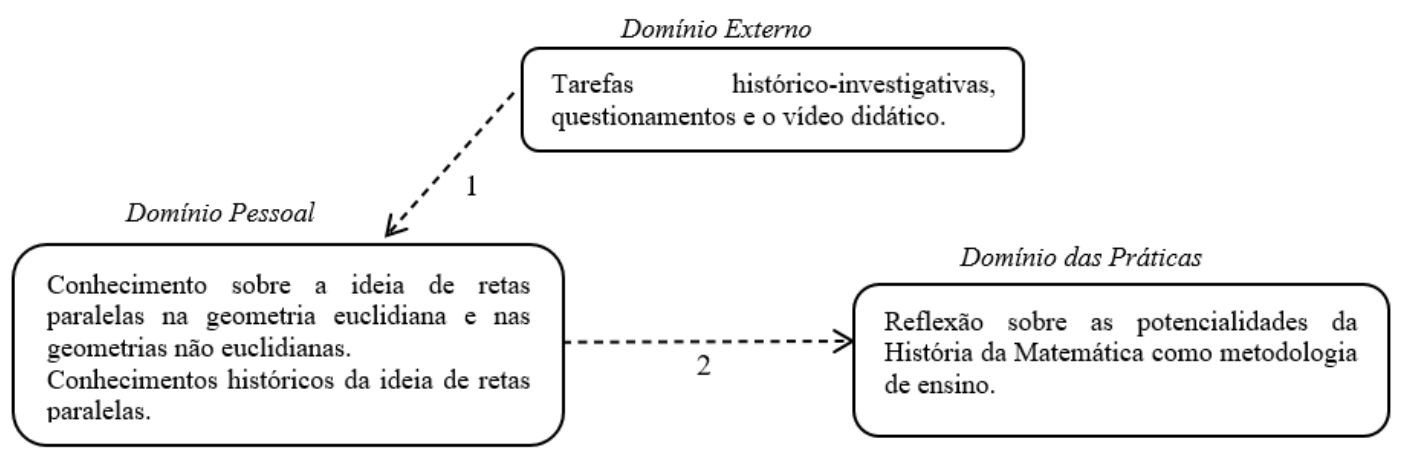

Os triângulos nas geometrias não euclidianas também foram explorados ao longo curso,

a abordagem deste tema aconteceu no segundo encontro. As tarefas exploradas sobre este

tópico foram as seguintes:

\section{Quadro 2.}

\section{Atividades sobre os triângulos nas geometrias não euclidianas}

\footnotetext{
Atualmente, um triângulo é definido como "Dados três pontos $A, B$ e $C$ não colineares, chama-se triângulo $A B C$ a reunião dos segmentos $A B, B C$ e $A C$ " (Iezzi, 2009, p.99).

No primeiro dos treze livros de $O s$ Elementos trouxe a ideia de triângulos, porém ele chama essa figura com três lados de triláteras a definindo como "E das figuras triláteras, por um lado, triângulo equilátero é o que tem os três lados iguais, e, por outro lado, isósceles, o que tem só dois lados iguais, enquanto escaleno, o que tem os três lados desiguais" (Bicudo, 2009, p.98).

1) Levando em consideração essas definições, vamos construir estas figuras:

a) Marque três pontos não colineares em uma folha de papel.

b) Ligue estes pontos.

c) A figura construída se trata realmente de um triângulo?

2) O matemático francês Henri Poincaré (1854 - 1912) criou um mapa que auxilia na visualização do plano hiperbólico. Esse mapa é um desenho gráfico que se propõe a representar, sobre uma superfície plana, o que existe na realidade em uma região acidentada.

Camargo (2012) afirma que o mapa de Poincaré é do tipo que os matemáticos chamam de mapa conforme. Nesse tipo de mapa, os ângulos são mantidos invariantes pela transformação. Isto é, se duas retas do espaço hiperbólico se cruzam e formam um ângulo qualquer, as representações dessas duas retas no mapa também se cruzam formando o mesmo ângulo. Assim, um triângulo nessa geometria ficou definido como: Três "retas" não colineares formam um triângulo $A B C$.
} 
Levando em consideração essa definição:

a) Marque três pontos sobre a superfície de biscuit.

b) Ligue estes pontos.

c) A figura construída se trata realmente de um triângulo?

3) Segundo Camargo (2012), considerando $A, B$ e $C$, três pontos distintos sobre uma esfera e não pertencentes a uma mesma circunferência máxima. Unindo esses pontos, dois a dois, por arcos de circunferências máximas, todos menores que uma semicircunferência, teremos um triângulo esférico $A B C$.

a) Pegue uma esfera de isopor e marque três pontos não colineares sobre sua superfície.

b) Ligue estes pontos.

c) A figura construída se trata realmente de um triângulo?

4) Os triângulos que você construiu nas duas superfícies (sela e isopor) permanecem com as mesmas características de um triângulo plano? Houve alguma deformação?

5) Sabe-se que a soma das medidas dos ângulos internos de um triângulo qualquer mede $180^{\circ}$, como afirma Iezzi (2009) Tomando esta afirmação como parâmetro, vamos verificar se esta propriedade é válida para as geometrias elíptica e hiperbólica.

a) Com o auxílio de um transferidor, meça os ângulos formados nas figuras, depois complete a tabela:

\begin{tabular}{|c|c|c|c|}
\hline X & Triângulo da atividade 1 & Triângulo da atividade 2 & Triângulo da atividade 3 \\
\hline Medida do ângulo 1 & & & \\
\hline Medida do ângulo 2 & & & \\
\hline Medida do ângulo 3 & & & \\
\hline Soma das medidas dos ângulos & & & \\
\hline
\end{tabular}

b) O que você conseguiu identificar sobre a soma dos ângulos internos dos triângulos?

c) Assim, quais as conclusões que você chegou?

As docentes finalizaram rapidamente as quatro primeiras tarefas, mas se demoraram um pouco na quinta por causa das medições com o transferidor (Figura 7).

Figura 7.

\section{Medindo os ângulos}

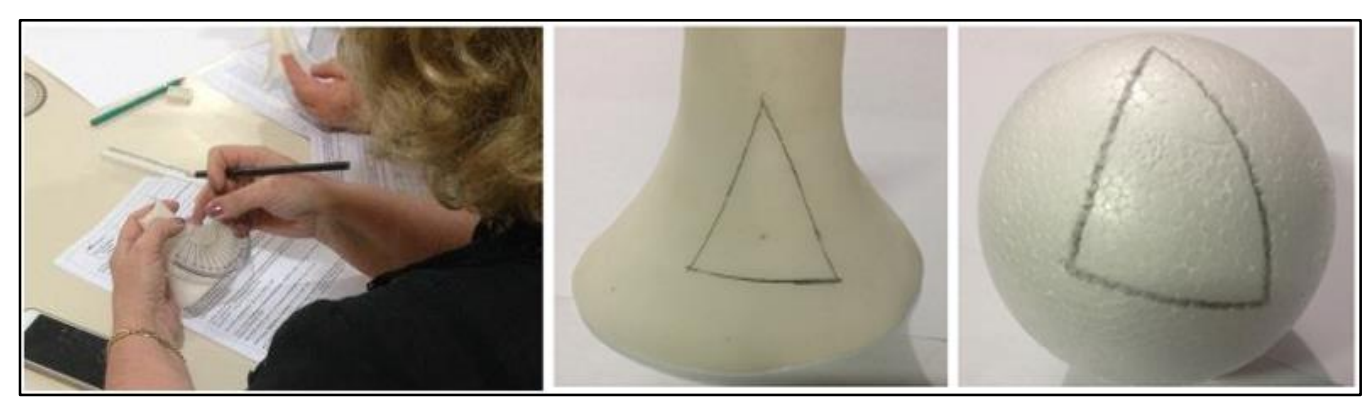

Elas deram sequência a realização do que se pedia: medir os ângulos dos três triângulos

e completar a tabela apresentada no Quadro 2 (Figura 8). 
Figura 8.

A medida dos ângulos

\begin{tabular}{|c|c|c|c|}
\hline$x$ & $\begin{array}{c}\text { Triângulo da } \\
\text { atividade } 1\end{array}$ & $\begin{array}{c}\text { Triângulo da } \\
\text { atividade 2 }\end{array}$ & $\begin{array}{c}\text { Triângulo da } \\
\text { atividade 3 }\end{array}$ \\
\hline $\begin{array}{c}\text { Medida do ângulo } \\
1\end{array}$ & $32^{\circ}$ & $35^{\circ}$ & $955^{\circ}$ \\
\hline $\begin{array}{c}\text { Medida do ângulo } \\
2\end{array}$ & $64^{\circ}$ & $83^{\circ}$ & $83^{\circ}$ \\
\hline $\begin{array}{c}\text { Medida do ângulo } \\
3\end{array}$ & $84^{\circ}$ & $54^{\circ}$ & $26^{\circ}$ \\
\hline $\begin{array}{c}\text { Soma das medidas } \\
\text { dos ângulos } \\
\text { internos }\end{array}$ & $180^{\circ}$ & $172^{\circ}$ & $204^{\circ}$ \\
\hline
\end{tabular}

Este momento foi marcado por um estranhamento generalizado entre o grupo.

P5: Opa! Tá errado! Gente o meu no triângulo do biscuit de $168^{\circ}$. Como pode?

P2: Tá estranho mesmo o meu deu $147^{\circ}$.

P3: Será que estamos medinho certo? Não sei não hein!

P4: Tem alguma coisa errada, não tem não? (Risos)

P4: Só essa que me faltava! Agora na bolinha está dando $192^{\circ}$. (Risos)

P2: Esse negócio é muito doido.

P3: Ah lá... O meu tá dando quase $200^{\circ}$. Não tinha que dar tudo $180^{\circ}$ ?

Percebe-se nas falas das professoras, que logo que elas começaram a realizar o que se pedia, perceberam que na folha de sulfite o resultado das somas eram $180^{\circ}$. Ao medirem os ângulos na superfície de biscuit, elas se mostraram confusas, pois viram o resultado da soma era menor que $180^{\circ}$. Então começaram a questionar e pedir ajuda, pois acreditavam estar erradas. Não queríamos influenciar nas conclusões e nas análises, por isso deixamos que elas discutissem. Terminadas as somas elas puderam perceber que no biscuit e na esfera de isopor o resultado da soma dos ângulos internos dos triângulos construídos não deu $180^{\circ}$, isto é, as medidas davam menores ou maiores. Após muitas discussões surge o seguinte diálogo:

P2: Gente! Olha posso estar errada, mas olha aqui... No biscuit de todo mundo deu menor e na bolinha de isopor deu maior.

P4: Nossa verdade, não tinha reparado nisso.

P2: Será que é isso? Será que tem algo a ver?

Assim, elas conseguiram chegar ao entendimento do que acontecia com aquelas figuras, nas respectivas superfícies. Em seguida foi exibido o vídeo "Os triângulos nas geometrias não 
euclidianas"8. Com ele foi possível formalizar que a soma dos ângulos internos de um triângulo irá variar de acordo com a geometria considerada: na euclidiana é $180^{\circ}$, na hiperbólica é menor que $180^{\circ}$ e na esférica é maior que $180^{\circ}$, podendo até chegar a $360^{\circ}$. Além desses aspectos, o vídeo explorou outras propriedades referentes aos triângulos nas geometrias hiperbólica e elíptica, como a medida dos lados que é feita em graus ou radianos e não em unidades de comprimento (mm, $\mathrm{cm}, \mathrm{m}$, etc.), a classificação dos triângulos quanto à medida dos lados e quanto às medidas dos ângulos internos, a ideia de semelhança, entre outros conceitos e propriedades.

P4: É! A partir de agora toda vez que eu falar de triângulos vou ter que tomar cuidado! Como que a gente sempre repete a mesma coisa: em qualquer triângulo a soma dos ângulos internos sempre será $180^{\circ}$.

P5: Verdade, nem sempre será.

P4: Estou até pensando em procurar meus ex-alunos pra pedir desculpas. (Risos)

P4: Verdade, temos que repensar isso.

P2: Nunca imaginei essas coisas... Essas outras possibilidades... É um mundo novo. $O$ que é pode não ser mais. É estranho.

P5: Quão rico seria também levar nossos alunos a verem essas coisas.

P4: Sim! Acho que seria muito interessante, mas ao mesmo tempo confuso. Será que não?

P1: Não! Acredito que não. Acho que se a gente souber levar eles a entender a superfície é tranquilo. Ela é a base.

P5: Com toda certeza, isso deveria ser o ponto de partida.

Nesta etapa, foi realizado o estudo dos triângulos nas geometrias não euclidianas, destacando os contributos do que foi produzido para o desenvolvimento profissional das professoras participantes. No decorrer desse processo, as atividades histórico-investigativas, bem como o vídeo didático proposto (domínio externo) possibilitaram estabelecer um ambiente de reflexão sobre o que elas conheciam e, também, sobre conceitos que elas desconheciam (domínio pessoal). Momento este em que elas puderam testar, verificar, construir, descontruir, criar hipóteses, enfim, um movimento marcado por experimentações, mas também por

\footnotetext{
${ }^{8}$ Disponível em: https://www.youtube.com/watch?v=YIW-q11QNhY. Acesso em: 01/04/2020.
} 
estranhamentos que foram fundamentais para a compreensão das ideias exploradas (vertente no conhecimento da matemática). Assim, esse processo de reflexão (seta tracejada 1 - Figura 9) foi o fio condutor não só para a construção de conhecimentos, mas permitiram que as professoras fossem levadas a refletir sobre o ensinar (seta tracejada 2 - Figura 9) a soma dos ângulos internos de um triângulo: o problema de dizer que essa soma sempre será $180^{\circ}$; já que é o que isso acontece na geometria euclidiana plana, mas em outras geometrias, no caso da hiperbólica e elíptica (geometrias não euclidianas), essa propriedade pode não ser válida. Além disso, foi dada a elas a oportunidade de refletir sobre o ensino destes conceitos em sala de aula, ou seja, na possibilidade de se explorar algumas noções das geometrias não euclidianas com os alunos, tanto no que diz respeito ao como abordar, quanto no que abordar (vertente do conhecimento da prática do ensino).

Figura 9.

Dinâmicas de aprendizagem das professoras sobre a temática dos triângulos

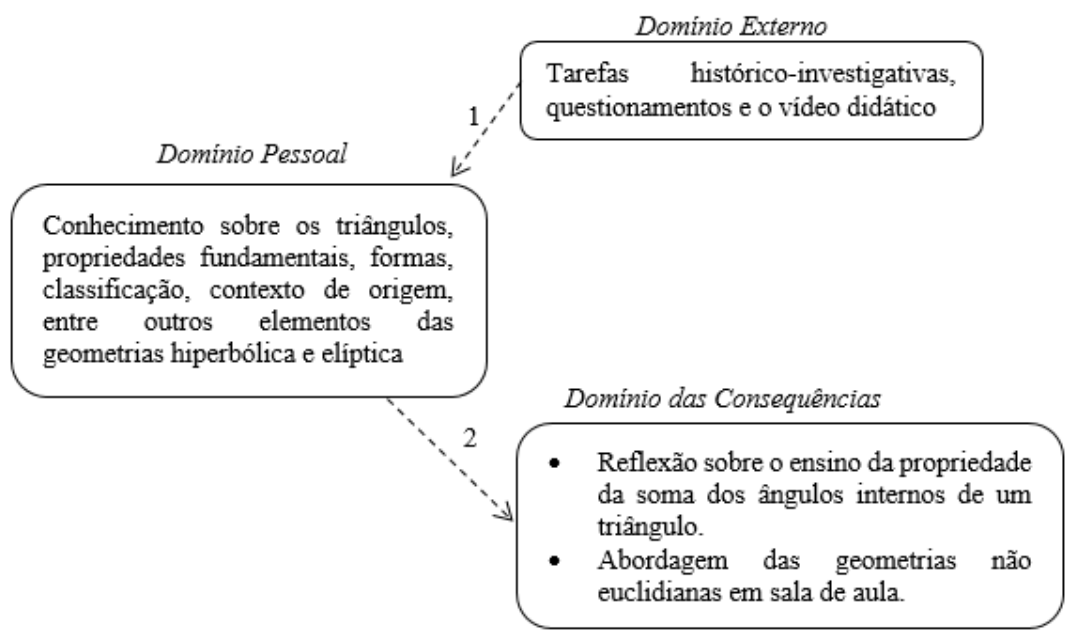

\section{Considerações finais}

Neste artigo tecemos algumas reflexões a respeito de um curso de formação continuada desenvolvido com seis professoras de Matemática sobre alguns conceitos básicos das geometrias não euclidianas, sob o enfoque da História da Matemática. Com a abordagem dada buscamos evidenciar que é possível pensar uma formação docente que explore os conceitos 
que compõem a Matemática escolar, mas que também possibilite um olhar pedagógico do como ensinar tais conceitos. Segundo Nacarato e Paiva (2017), quando esse tipo de abordagem acontece o professor pode desenvolver seus conhecimentos sobre o fazer pedagógico. Além de levar à uma reflexão sobre alguns conceitos das geometrias não euclidianas, que ainda são pouco abordados na formação inicial e continuada de professores.

O modelo inter-relacional de desenvolvimento profissional proposto por Clarke e Hollignworth (2002) sugere que os questionamentos, as tarefas, as discussões, os vídeos, as investigações realizadas possibilitaram diversas reflexões que provocaram alterações não só nos conhecimentos matemáticos das professoras, mas também nos conhecimentos relacionados ao fazer pedagógico, principalmente, no que diz respeito ao ensino da geometria, as dificuldades encontradas e sobre a própria História da Matemática.

Em síntese, no primeiro momento do curso, em sua maioria, as professoras não conseguiam explicitar o que eram as geometrias não euclidianas. Mas com a abordagem dada a partir das atividades histórico-investigativas e do vídeo didático proposto (Domínio Externo) serviu de elemento desencadeador (Seta tracejada 1 na Figura 4) de aprendizagens relacionadas ao que são as geometrias não euclidianas e como elas surgiram (Domínio Pessoal), além disso serviu de fonte para outras reflexões (Seta tracejada 2 na Figura 4): o ensino da geometria, as lacunas de aprendizagem e as dificuldades dos alunos (Domínio das Consequências).

Já no segundo tópico abordado, o das retas paralelas, as atividades investigativas que impunha a mesma construção em diferentes superfícies e vídeo sob uma abordagem histórica (Domínio Externo) serviram como elementos desencadeadores de reflexões (Seta tracejada 1 na Figura 6) que permitiram romper com a ideia de paralelismo que elas já tinham internalizada, fundamentada na geometria euclidiana na qual dada uma reta e um ponto fora dela existirá uma única reta paralela à reta dada passando por esse ponto; levando a compreensão de que podem existir infinitas retas paralelas a reta dada passando por esse ponto ou podem não existir retas 
paralelas, entre tantos outros elementos (Domínio Pessoal). Tais aspectos permitiram o raciocínio sobre outros elementos (Seta tracejada 2 na Figura 6), relacionados às potencialidades do uso História da Matemática metodologia de ensino (Domínio das Práticas). Por fim, abordou-se as dinâmicas de aprendizagem sobre os triângulos. Neste estudo, com a proposta de atividades histórico-investigativas e com o vídeo didático (Domínio Externo) foi possível instigar as professoras para o estranhamento (Seta tracejada 1 na Figura 9) que levou a compreensão de que a soma dos ângulos internos de um triângulo nem sempre é $180^{\circ}$, podendo ser maior ou menor; entre tantos outros entendimentos que foram possibilitados (Domínio Pessoal). Esses conhecimentos adquiridos fomentaram reflexões (Seta tracejada 2 na Figura 9) a respeito desta propriedade da soma dos ângulos internos do triângulo, bem como sobre a possibilidade de se abordar as geometrias não euclidianas na Educação Básica (Domínio das Consequências).

Como pode ser observado, esta análise se baseou na dimensão da reflexão (identificada por setas tracejadas) do modelo de Clarke e Hollignworth (2002), uma vez que a materialização (identificada por setas contínuas) está diretamente relacionada ao momento em que os conhecimentos adquiridos por intermédio da reflexão são levados para a sala de aula, isto é, são empregados na prática, o que não foi fomentado ao longo do curso.

Neste viés, os modelos apresentados por Ponte (2012), sobre o conhecimento profissional do professor de Matemática, e por Clarke e Hollignworth (2002), sobre o desenvolvimento profissional, nos ajudaram a compreender que as ações e atividades realizadas ao longo curso de formação continuada proposto permitiram o desenvolvimento do conhecimento das professoras cursistas. Para além do pensar sobre as geometrias não euclidianas, as professoras tiveram de refletir sobre a geometria euclidiana plana ampliando, assim, seus conhecimentos geométricos. Cabe salientar a possibilidade de vivenciar o uso pedagógico da História da Matemática e suas potencialidades, que para elas foi algo de grande 
valia e que deu o incentivo de levá-la para suas práticas docentes. Ademais, outro aspecto a ser ponderado é o fato das professoras se permitirem discutir as próprias dificuldades com a geometria, os problemas de aprendizagem dos alunos, o ensino da geometria, a inserção das geometrias não euclidianas nas aulas de Matemática da Educação Básica, entre outros aspectos sem serem motivadas a falar sobre.

Conclui-se destacando que as dinâmicas de aprendizagem foram marcadas pela reflexão, possibilitada em grande parte pela História da Matemática e pela natureza das tarefas, que deram origem a aprendizagem em diversos aspectos do conhecimento matemático e didático (Ponte, 2012).

\section{Referências}

Araman, E. M. O. (2011). Contribuições da história da matemática para a construção dos saberes do professor de matemática [Tese de doutorado em Ensino de Ciência e Educação Matemática, Universidade Estadual de Londrina]. Disponível em: http://www.bibliotecadigital.uel.br/document/?view=vtls000168190.

Araman, E. M. O. \& Batista, I. L. (2013). Contribuições da história da matemática para a construção dos saberes do professor de matemática. Bolema: Boletim de Educação Matemática, $27 \quad$ (45), $\quad$ p. 1-30. Disponível em: https://www.scielo.br/pdf/bolema/v27n45/v27n45a02.pdf.

Batista, I. L. \& Luccas, S. (2004). Abordagem histórica-filosófica e Educação Matemática uma proposta de interação entre domínios de conhecimento. Educação Matemática Pesquisa, 6 (1), p. 101-133. Disponível em: http://www.uel.br/grupopesquisa/ifhiecem/arquivos/4682-10997-1-PB.pdf.

Bicudo, I. (2009). (tradutor e organizador). Os elementos. São Paulo: Editora da UNESP.

Bogdan, R. \& Biklen, S. K. (1994). Investigação qualitativa em educação. Porto, Portugal: Porto Editora.

Brito, A. J. \& Carvalho, D. L. (2009). Utilizando a história no ensino de geometria. In: A. Miguel; A. J. Brito; D. L. Carvalho; I. A. Mendes. (org.). História da matemática em atividades didáticas (pp.13-104). São Paulo: Livraria da Física.

Camargo, K. C. A. (2012). A expressão gráfica e o ensino de geometrias não euclidianas [Dissertação de mestrado em Educação em Ciências e Matemática, Universidade Federal do Paraná]. Disponível em: http://www.educadores.diaadia.pr.gov.br/arquivos/File/dezembro2012/matematica_art igos/dissertacao_keilacacamargo.pdf.

Chavichiolo, C. V. (2011). Geometrias não euclidianas na formação inicial do professor de matemática: o que dizem os formadores [Dissertação de mestrado em Educação, 
Universidade Federal do Paraná]. Disponível em: https://acervodigital.ufpr.br/handle/1884/26964.

Clarke, D. \& Hollingsworth, H. (2002). Elaborating a model of teacher professional growth. Teaching and teacher education, 18 (8), p. 947-967. https://doi.org/10.1016/S0742051X(02)00053-7.

Day, C. (2001) Desenvolvimento profissional de professores: os desafios da aprendizagem permanente. Porto, Portugal: Porto Editora.

Goetz,J. \& LeCompte, M. (1984). Ethnography and Qualitative Design in Education Research. San Diego, CA: Academic Press.

Guskey, T. R. \& Huberman, M. (1995). Professional development in education: new paradigms and practices. New York: Teachers College Press.

Heideman, C. (1990). Introduction to staff development: programming for staff development. London: Falmer Press.

Marqueze, J. P. (2006). As faces dos sólidos platônicos na superfície esférica: uma proposta para o ensino-aprendizagem de noções básicas da geometria esférica [Dissertação de mestrado em Educação, Pontifícia Universidade Católica - São Paulo]. Disponível em: https://tede2.pucsp.br/bitstream/handle/11134/1/dissertacao_joao_pedro_marqueze.pd f.

Mendes, I. A. \& Chaquiam, M. (2016). História nas aulas de Matemática: fundamentos e sugestões didáticas para professores. Belém: SBHMat.

Miguel, A. (2005). História, filosofia e sociologia da educação matemática na formação do professor: um programa de pesquisa. Educação e Pesquisa, 31 (1), p. 137-152. Disponível em: https://www.scielo.br/pdf/ep/v31n1/a10v31n1.pdf.

Miguel, A. \& Miorim, M. Â. (2019). História na educação matemática. São Paulo: Autêntica Editora.

Nacarato, A. M. \& Paiva, M. A. V. (2017). A formação do professor que ensina matemática: perspectivas e pesquisas. São Paulo: Autêntica.

Nascimento, A. K. S. (2013). Geometrias não euclidianas como anomalias: implicações para o ensino de geometria e medidas [Dissertação de mestrado em Ensino de Ciências e Matemática, Universidade Federal do Rio Grande do Norte]. Disponível em: https://repositorio.ufrn.br/jspui/bitstream/123456789/16107/1/AnnaKSN_DISSERT.p df.

Ponte, J. P. (1994). O professor de matemática: um balanço de dez anos de investigação. Quadrante, 3 (2), p. 79-114. Disponível em: https://quadrante.apm.pt/index.php/quadrante/article/view/403/346.

. (1998). Da formação ao desenvolvimento profissional. ACTAS do PROFMAT, $27-$ 44. Disponível em: http://www.educ.fc.ul.pt/docentes/jponte/docs-pt/98Ponte(Profmat).doc.

(2012). Estudiando el conocimiento y el desarrollo profesional del profesorado de matemáticas. In: N. Planas (coord.). Teoría, crítica y práctica de la educación matemática (p. 83-98). Disponível em: https://repositorio.ul.pt/bitstream/10451/29194/1/Ponte\%20PROFESORADO_\%2831 _Ago_2011\%29F.pdf. 
Ponte, J. P.; Mata-Pereira, J.; Quaresma, M. \& Velez, I. (2017). Formação de professores dos primeiros anos em articulação com o contexto de prática de ensino de matemática. Revista latinoamericana de investigación en matemática educativa, 20 (1), p. 71-94. Disponível em: http://www.scielo.org.mx/scielo.php?script=sci_arttext\&pid=S166524362017000100071.

Quaresma, M. \& Ponte, J. P. (2017). Dinâmicas de aprendizagem de professores de Matemática no diagnóstico dos conhecimentos dos alunos num estudo de aula. Quadrante, 26 (2), p. 43-68. Disponível em: https://repositorio.ul.pt/bitstream/10451/36479/1/Quaresma\%20\%26\%20Ponte_Quadr ante $\% 20 \mathrm{Vol} \% 202 \% 202017 . p d f$.

Reis, J. D. S. (2006). Geometria esférica por meio de materiais manipuláveis [Dissertação de mestrado em Educação Matemática, Universidade Estadual Paulista - Rio Claro]. Disponível em: https://repositorio.unesp.br/handle/11449/91152.

Ribeiro, R. D. G. L. (2012). O ensino das geometrias não euclidianas: um olhar sob a perspectiva da divulgação científica [Dissertação de mestrado em Ensino de Ciências e Matemática, Universidade de São Paulo]. Disponível em: https://www.teses.usp.br/teses/disponiveis/48/48134/tde-21012013-154441/pt-br.php.

Strutchens, M.; Huang, R.; Losano, L.; Portari, D.; Ponte, J. P.; Cyrino, M. C. C. T. \& Zbiek, R. M. (2016). The mathematics education of prospective secondary teachers around the world. Springer Open. Disponível em: https://link.springer.com/content/pdf/10.1007\%2F978-3-319-38965-3.pdf.

Recebido em: 15/04/2020

Aprovado em: 22/05/2020 